\title{
MAPEAMENTO DO EMPREGO FORMAL FEMININO NO ESTADO DO PARANÁ
}

\author{
MAPPING WOMEN'S FORMAL EMPLOYMENT \\ IN THE PARANÁ STATE, BRAZIL
}

\author{
Ivanete Daga Cielo* \\ Jandir Ferrera de Lima** \\ Lucir Reinaldo Alves ${ }^{* * *}$
}

\begin{abstract}
RESUMO
O objetivo desse artigo é analisar e mapear o emprego formal feminino no Estado do Paraná. O período de análise foi entre 1985 e 2010. A partir dos dados obtidos, foi possível inferir que houve aumento do número de mulheres no mercado de trabalho, passando de uma participação de $31 \%$ em 1985 para $43 \%$ do emprego formal no Estado do Paraná em 2010, reforçando, assim, a evidência empírica de aumento de participação da mulher no mercado de trabalho e a redução do diferencial em relação aos homens. Esse crescimento é resultado principalmente de mudanças econômicas, queda da taxa de fecundidade e do aumento no nível de instrução da população feminina.
\end{abstract}

Palavras-chave: Emprego formal. Gênero. Mulheres. Desenvolvimento.

\begin{abstract}
The aim of this paper is to analyze and map women's formal employment in the state of Paraná. The period analyzed was from 1985 to 2010. It was possible to infer from the data obtained that there was an increase in the number of women in the labor market through a participation of $31 \%$ in 1985 to $43 \%$ of formal employment in the state of Paraná. This reinforces the empirical evidence of increased participation of women in the labor market and the reduction in the ratio of working women/men. This growth is mainly the result of economic changes, decline in fertility and increase in the level of education of the female population.
\end{abstract}

Keywords: Formal employment. Gender. Women. Development.

\footnotetext{
* Mestre em Engenharia de Produção pela Universidade Federal de Santa Catarina (UFSC), professora assistente da Universidade Estadual do Oeste do Paraná (Unioeste)/Campus de Toledo. Doutoranda do Programa de Pós-Graduação em Desenvolvimento Regional e Agronegócio da Universidade Estadual do Oeste do Paraná (Unioeste). Email: ivacielo@unioeste.br.

${ }^{* *}$ Ph.D. em Desenvolvimento Regional pela Université du Québec (UQAC)/Canadá, professor adjunto do Programa de Pós-Graduação em Desenvolvimento Regional e Agronegócio da Universidade Estadual do Oeste do Paraná (Unioeste)/Campus de Toledo. Pesquisador do Grupo de Pesquisa em Desenvolvimento Regional e Agronegócio (Gepec). Emails: jandir@unioeste.bre jandirbr@yahoo.ca.

${ }^{* * *}$ Mestre em Desenvolvimento Regional pela Universidade de Santa Cruz do Sul (Unisc). Professor da Universidade Estadual do Oeste do Paraná (Unioeste/ Campus de Toledo). Pesquisador do Grupo de Pesquisas em Desenvolvimento Regional e Agronegócio (Gepec). E-mails: lucir_a@hotmail.com e lucir. alves@unioeste.br.
} 


\section{Introdução}

Ao longo das últimas décadas do século XX, inúmeras mudanças ocorreram na economia mundial, com impactos diretos sobre as relações de comércio, produção e trabalho. Essas mudanças igualmente aconteceram no Brasil, constituindo assim um ambiente favorável para a entrada de novos trabalhadores no mercado de trabalho, principalmente em função da expansão de atividades.

No Brasil, a intensificação da participação das mulheres na atividade econômica ocorreu a partir de 1970 e prosseguiu na década de 1980, apesar da estagnação da atividade econômica e da deterioração das oportunidades de ocupação. Nos anos 1990, década caracterizada pela intensa abertura econômica, pelos baixos investimentos e pela terceirização da economia, continuou a tendência de crescente incorporação da mulher na força de trabalho (HOFFMANN; LEONE, 2004).

No entanto, a inserção da mulher no mercado de trabalho, além das questões econômicas, também foi impulsionada em virtude de questões demográficas, culturais e sociais. Entre os aspectos demográficos destaca-se a queda da taxa de fecundidade, sobretudo nas cidades e nas regiões mais desenvolvidas, a redução no tamanho das famílias, o envelhecimento da população, com maior expectativa de vida às mulheres, e o acentuado crescimento de arranjos familiares chefiados por mulheres. Além dessas transformações demográficas, mudanças nos padrões culturais e nos valores relativos ao papel social da mulher alteraram a identidade feminina, cada vez mais voltada para o trabalho remunerado. Ao mesmo tempo, a expansão da escolaridade e o ingresso nas universidades viabilizaram o acesso delas a novas oportunidades de trabalho. Todos esses fatores explicam não apenas o crescimento da atividade feminina, mas também as suas transformações no perfil da força de trabalho (BRUSCHINI, 2007).

Em relação ao perfil das mulheres no mercado de trabalho, Hoffmann e Leone (2004) mencionam que, na década de 1970, as trabalhadoras eram, na sua maioria, jovens, solteiras e pouco escolarizadas. Na década de 1980, as mulheres com idade acima de 25 anos, com níveis mais elevados de instrução e nível de renda não muito baixo, foram as que mais aumentaram a participação no trabalho remunera- do. Nos anos 1990, a continuidade da ampliação das taxas de participação feminina, sobretudo entre mulheres intensificou-se, estreitando o mercado de trabalho para os jovens. A partir de 1990, a força de trabalho assumiu definitivamente um novo perfil: mais adulta, instruída e com uma parcela feminina maior.

Nesse contexto de crescente participação das mulheres no mercado de trabalho e no intuito de corroborar, buscando a melhor compreensão deste quadro, este estudo pretende, a partir dos dados disponibilizados na Relação Anual de Informações Sociais - Rais, do Ministério do Trabalho e Emprego (MTE), mapear o emprego formal feminino nas distintas microrregiões do Estado do Paraná.

Objetiva-se, ainda, analisar a evolução recente da inserção feminina na estrutura produtiva das 39 microrregiões paranaenses no período compreendido entre 1985 e 2010, apontando alterações não apenas na intensidade de engajamento das mulheres no mercado de trabalho, como também os setores que mais empregam comparativamente ao contingente masculino.

\section{Participação das mulheres no mercado de trabalho}

O desenvolvimento econômico e o aumento dos índices de escolaridade, aliados às mudanças demográficas e sociais, alteraram o papel feminino no mercado de trabalho. No entanto, por muito tempo, a participação da mulher na constituição da renda familiar foi completamente invisível. O trabatho feminino era considerado sem valor produtivo ou como ajuda, e por muitos anos elas dedicaram-se exclusivamente às tarefas domésticas, ao cuidado dos filhos e do marido, enfim às tarefas que garantiam a manutenção da estrutura familiar (HEREDIA; CINTRÃO, 2006).

A partir da década de 1970, com os movimentos feministas, as reivindicações pelo reconhecimento do papel e do espaço que a mulher ocupava na sociedade ficaram mais constantes, tomando força a cada década que se seguia. Para Bruschini (2007), as transformações nos padrões culturais e nos valores relativos ao papel social da mulher, intensificadas pelos impactos dos movimentos feministas dos anos 1970 e pela presença cada vez mais atuante das 
mulheres nos espaços públicos, alteraram a constituição da identidade feminina, cada vez mais voltada para o trabalho produtivo.

Para Borges e Guimarães (2000), essa crescente participação na oferta de força de trabalho resulta das mudanças ocorridas na relação historicamente existente entre a esfera pública e privada ou nas esferas de produção e reprodução. Contudo, essa admissão das mulheres no sistema produtivo deu-se, principalmente, através de atividades laborais que podem ser desenvolvidas no ambiente familiar ou domiciliar.

As mulheres continuam a prevalecer no trabalho a domicílio, uma vez que carecem de mobilidade e de flexibilidade de opções no mercado de trabalho. Tanto em virtude do viés de gênero presente nas definições de postos de trabalho como pelas responsabilidades familiares que recaem sobre elas e seus fortes vínculos comunitários, as mulheres constituem a principal oferta de trabalho a domicílio (LAVINAS; SORJ, 2000).

No entanto, de acordo com Mello (2011), nas ultimas décadas as mulheres foram massivamente ao mercado de trabalho, mas as desigualdades existentes na sociedade permitiram tal incorporação sem que isso provocasse maiores mudanças nas relações de gênero, ou seja, continua existindo trabalho "de homem" e trabalho "de mulher".

Garcia e Conforto (2010) também alertam para as questões de desigualdade de gênero ao afirmarem que o estímulo à inserção feminina no mercado de trabalho ainda se dá em condições adversas, em uma cultura econômica centrada no poder masculino. As desigualdades de gênero são perceptíveis na esfera política, educacional e no mundo do trabalho, embora no Brasil muito se tenha avançado na inserção feminina nesses espaços. Porém, no que se refere às condições de entrada e permanência no mercado de trabalho e na remuneração pelas atividades desenvolvidas, as disparidades entre gêneros são latentes.

As diferenciações entre mulheres e homens no mercado de trabalho podem ser visualizadas no Quadro 1, a seguir:
Quadro 1 - Principais indicadores de condição de atividade e de ocupação da população de 10 anos ou mais de idade para o Brasil em 2009, segundo o sexo.

\begin{tabular}{|l|c|c|}
\hline \multicolumn{1}{|c|}{ VARIÁVEL } & HOMENS & MULHERES \\
\hline $\begin{array}{l}\text { Taxa de atividade - } \\
\text { (percentagem da PEA em } \\
\text { relação ao total de pessoas) }\end{array}$ & $72,3 \%$ & $52,7 \%$ \\
\hline $\begin{array}{l}\text { Nível de ocupação - (percent- } \\
\text { agem de pessoas ocupadas em } \\
\text { relação ao total de pessoas) }\end{array}$ & $67,8 \%$ & $46,8 \%$ \\
\hline $\begin{array}{l}\text { Taxa de desocupação - } \\
\text { (percentagem das pessoas } \\
\text { desocupadas em relação à } \\
\text { PEA) }\end{array}$ & $6,2 \%$ & $11,1 \%$ \\
\hline $\begin{array}{l}\text { Distribuição da PEA - } \\
\text { população economicamente } \\
\text { ativa (ocupadas e } \\
\text { desocupadas) }\end{array}$ & $56,1 \%$ & $43,9 \%$ \\
\hline $\begin{array}{l}\text { Distribuição das pessoas } \\
\text { ocupadas }\end{array}$ & $57,4 \%$ & $42,6 \%$ \\
\hline
\end{tabular}

Fonte: Pnad, 2009.

Mesmo com os consideráveis avanços obtidos pelas mulheres no mercado de trabalho, os dados expostos no Quadro 1 demonstram níveis inferiores de ocupação das mulheres em relação aos homens, comprovando, assim, que as diferenças de gênero permanecem latentes quando se trata de inserção no mercado de trabalho.

Em relação aos aspectos educacionais, a expansão da escolaridade, à qual as brasileiras têm tido cada vez mais acesso, é um dos fatores de maior impacto sobre o ingresso das mulheres no mercado de trabalho. A escolaridade das trabalhadoras é muito superior à dos trabalhadores, diferencial de gênero que se verifica também na população em geral. Ao mesmo tempo, a escolaridade elevada tem impacto considerável sobre o trabalho feminino, pois as taxas de atividade das mais instruídas são muito mais elevadas do que as taxas gerais de atividade das menos instruídas (BRUSCHINI, 2007).

Ao longo do período de 2001 a 2010, de acordo com os dados do Censo da Educação Superior (2010), as matrículas no ensino superior contaram com participação majoritariamente feminina. Igualmente, a participação feminina demonstra-se ainda 
superior quando se considera os concluintes do ensino superior. Em 2010, do total de 6.379.299 matrículas, $57,0 \%$ são femininas e, entre os concluintes, a participação feminina é de $60,9 \%$.

Entretanto, mesmo com nível de instrução mais elevado, as mulheres têm salários inferiores em relação aos homens, conforme demonstra o Gráfico 1.

Gráfico 1 - Média salarial entre homens e mulheres 2010

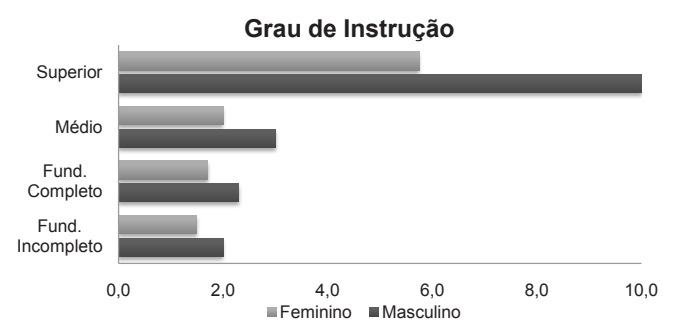

Fonte: IBGE/ Senso demográfico 2010.

De acordo com os dados do Censo Demográfico (2010), o grau de instrução das mulheres é superior ao dos homens; no entanto, na medida em que aumenta a escolaridade das mulheres, aumenta também a disparidade de renda entre homens e mulheres. Para trabalhadores com escolaridade entre ensino médio completo e superior incompleto, a faixa salarial dos homens já é ligeiramente maior, de três salários e meio. As mulheres recebem, em média, dois salários mínimos na maior parte do país. Tais dados apontam para um cenário em que há a constatação de que, na economia, as diferenças de gênero ainda permanecem no mercado de trabalho, embora venham diminuindo ao longo do tempo.

\section{Gênero e desenvolvimento regional}

Os estudos que abordam questões regionais precedem inicialmente de definições acerca do conceito de região. Assim, uma região pode ser definida como unidade de análise, representada por um conjunto de pontos do espaço integrados entre si, dotados de um determinado grau de integração em oposição ao resto do mundo (LEMOS, 1988).

Para Boudeville (1970), o conceito de região corresponde a um espaço contínuo onde cada uma de suas partes apresenta características semelhantes.
É um espaço heterogêneo, onde as diversas partes são complementares, em um sistema hierarquizado de acordo com os bens produzidos (local, regional e/ ou nacional). O espaço geográfico pode ser definido também como o suporte de uma sociedade e de uma economia, e, como tal, é objeto de apropriação e lugar onde se desenvolvem as estratégias dos grupos sociais. Nesta interpretação, admite-se que os espaços e suas sociedades podem ser conceituados como regiões. Para Andrade (1973), o espaço é dividido de acordo com as características que apresenta em suas várias porções, levando em conta, sobretudo, as características oriundas da influência das condições naturais e do aproveitamento do espaço.

Fortin (2002) avança em conceituar regiões ao afirmar que uma região é um dos lugares de identidade e de pertencimento e frequentemente lugar de enraizamento, e que as populações, para se fixarem em determinada região, além de obterem empregos, é necessário que se sintam realizadas profissionalmente. Para o autor, o desenvolvimento regional tem componentes econômicos, mas também identitários, não ficando restritos à criação de empregos, mesmo que esta permaneça como a base para o desenvolvimento. Os empregos podem ser em indústrias, baseados em recurso, mas podem igualmente ser estruturados sobre os meios de comunicação existentes, contribuindo para a definição da identidade e da cultura regional. Fortin (2002) afirma que desenvolver uma região é fazer dela um lugar onde se vive com qualidade de vida, envolvendo todos os gêneros.

Sen (2001) sinaliza a importância das questões de gênero e desenvolvimento, de modo específico a participação das mulheres no processo de desenvolvimento, ao afirmar que o ganho de poder das mulheres é um dos aspectos centrais no processo de desenvolvimento em muitos países no mundo atual. $\mathrm{O}$ autor salienta também que "A condição de agente das mulheres é um dos mediadores da mudança econômica e social, e sua determinação e suas consequências relacionam-se estreitamente a muitas das características centrais do processo de desenvolvimento (SEM, 2000, p.234- 5).

Nesse sentido, os estudos de desenvolvimento e gênero ganham importância, uma vez que de acordo com o Instituto Internacional de Pesquisa e Capacitação das Nações Unidas para a promoção 
das Mulheres (INSTRAW) (1995), citado por Staduto et al., (2009), as relações de gênero devem ser observadas na busca pelo desenvolvimento, considerando as diferenças entre homens e mulheres na definição de estratégias de desenvolvimento, de políticas públicas entre outras, sob pena de se basear em considerações imperfeitas se assim não se proceder.

\section{Aspectos metodológicos}

Considerando as transformações do papel da mulher na economia, na família e na sociedade nos últimos anos, o objetivo do presente estudo é mapear o emprego formal feminino nas distintas microrregiões do Estado do Paraná. Pretende-se, igualmente, analisar a evolução recente da inserção feminina na estrutura produtiva das microrregiões paranaenses no período compreendido entre 1985 e 2010, utilizando-se, para tanto, dos dados disponibilizados na Relação Anual de Informações Sociais - RAIS/MTE, apontando alterações não apenas na intensidade de engajamento das mulheres no mercado de trabalho, como também os setores que mais as empregam e as desigualdades ocupacionais, comparativamente ao contingente masculino.

Salienta-se que, no período de analise, década de 1980 até 2010, de acordo com Piffer e Arend (2008), o Estado do Paraná sofreu inúmeras mudanças econômicas e sociais, tais como a integração da economia paranaense com a nacional e com a internacional, a modernização da agropecuária, o esgotamento da fronteira agrícola e a ampliação, difusão e diversificação dos ramos industriais, contribuindo para a formação de uma nova configuração geoeconômica no Estado do Paraná.

Para a análise, o Estado do Paraná foi dividido em 39 microrregiões (MRG): Paranavaí (MRG01); Umuarama (MRG02); Cianorte (MRG03); Goioerê (MRG04); Campo Mourão (MRG05), Astorga (MRG06); Porecatu (MRG07); Florai (MRG08); Maringá (MRG09); Apucarana (MRG10); Londrina (MRG11); Faxinal (MRG12); Ivaiporã (MRG13); Assai (MRG14); Cornélio Procópio (MRG15); Jacarezinho (MRG16); Ibaiti (MRG17); Wenceslau Braz (MRG18); Telêmaco Borba (MRG19); Jaguariaíva (MRG20); Ponta Grossa (MRG21); Toledo (MRG22); Cascavel (MRG23); Foz do
Iguaçu (MRG24); Capanema (MRG25); Francisco Beltrão (MRG26); Pato Branco (MRG27); Pitanga (MRG28); Guarapuava (MRG29); Palmas (MRG30); Prudentópolis (MRG31); Irati (MRG32); União da Vitória (MRG33); São Mateus do Sul (MRG34); Cerro Azul (MRG35); Lapa (MRG36); Curitiba (MRG37); Paranaguá (MRG38); e Rio Negro (MRG39). Uma microrregião geográfica é definida, de acordo com Hespanhol (1996), como parte de uma mesorregião que apresenta características específicas em relação à organização do espaço, as quais se refletem na estrutura de produção, agropecuária, industrial, extrativismo mineral ou pesca.

A distribuição espacial das microrregiões do Estado pode ser visualizada na Figura 1.

No que tange aos procedimentos de coleta e análise de dados, inicialmente buscou-se o número de empregos formais femininos e masculinos distribuídos por setores nas 39 microrregiões do Estado do Paraná. Salienta-se que os dados referentes ao quantitativo de empregos registrados foram coletados no banco de dados on-line da Relação Anual das Informações Sociais (RAIS), do Ministério do Trabalho e Emprego (MTE), e fez-se uma análise setorial com base nos Subsetores de Atividade Econômica, definidos segundo o IBGE (26 categorias). Os subsetores analisados são: Extrativa mineral; Indústria de produtos minerais não metálicos; Indústria metalúrgica; Indústria mecânica; Indústria do material elétrico e de comunicações; Indústria do material de transporte; Indústria da madeira e do mobiliário; Indústria do papel, papelão, editorial e gráfica; Indústria da borracha, fumo, couros, peles, similares; Indústria diversas; Indústria química de produtos farmacêuticos, veterinários, perfumaria; Indústria têxtil do vestuário e artefatos de tecidos; Indústria de calçados; Indústria de produtos alimentícios, bebidas e álcool etílico; Serviços industriais de utilidade pública; Construção civil; Comércio varejista; Comércio atacadista; Instituições de crédito, seguros e capitalização; Comércio e administração de imóveis, valores mobiliários, serviços técnicos; Transportes e comunicações; Serviços de alojamento, alimentação, reparação, manutenção, redação; Serviços médicos, odontológicos e veterinários; Ensino; Administração pública direta e autárquica; e Agricultura, silvicultura, criação de animais, extrativismo vegetal. 
Figura 1 - Microrregiões geográficas do Estado do Paraná

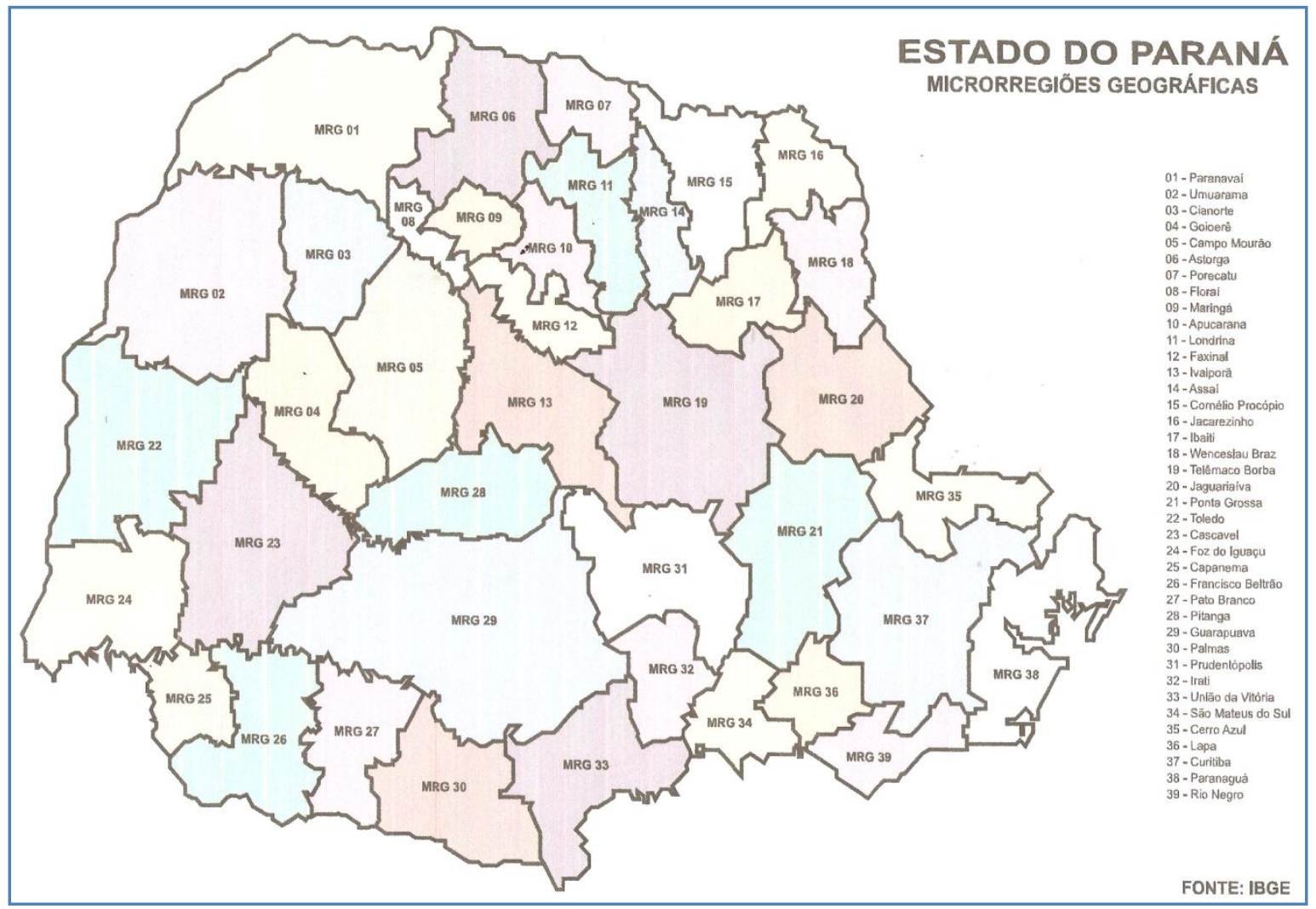

Para facilitar a visualização da distribuição espacial dos empregos formais femininos entre as microrregiões, os dados serão apresentados em forma de mapas temáticos, utilizando-se para isso o software TerraView.

\section{Resultados e discussões}

Conforme afirmam Piffer e Arend (2008), a integração econômica do Paraná, tanto nacional quanto internacionalmente, estimulou atividades que dinamizam outros ramos da economia, gerando mais empregos, ampliando o mercado consumidor e criando novas demandas para os produtos agropecuários e industriais paranaenses. Dessa forma, dinamizou-se a estrutura produtiva do Estado, deixando de ser uma economia voltada apenas à produção agrícola, aumentando a base de exportação, diversificando e difundindo os seus ramos industriais.

A expansão das fronteiras agrícolas no Paraná ocorreu de forma mais acentuada a partir de 1980, impulsionando a formação de cidades e a moderni- zação do espaço rural. Na década seguinte (1990), com a consolidação das principais cidades polos do Estado, a economia paranaense reestruturou-se, fortalecendo, assim, as especificidades regionais (GONÇALVES JUNIOR, 2011).

De acordo com Alves et al. (2011), o processo de desenvolvimento regional é impulsionado, num primeiro momento, pelo desenvolvimento do setor primário; porém, ao longo do processo ele vai perdendo espaço na geração de emprego e produto para os setores urbanos (secundário e terciário).

Os dados do Caged (2011) apontam ainda que na última década o país experimentou uma reação forte do mercado formal de trabalho, com elevação contínua da participação dos trabalhadores em atividades urbanas. Mesmo com o decréscimo de alguns setores econômicos, tal como o de indústria de transformação, o aumento do setor de serviços tem contribuído para o crescimento e manutenção dos postos de trabalho formal no país.

O Estado do Paraná, acompanhando os índices de crescimento do emprego formal no país, no ano de 2010, de acordo com os dados da RAIS 
(2010), alcançou aproximadamente 2,8 milhões de empregos, como resultado do crescimento de 5,53\% em relação ao estoque de emprego de dezembro de 2009. Em termos absolutos, essa performance decorreu do acréscimo de 145,9 mil postos de trabalho em relação a dezembro do ano anterior, sendo que os setores de serviços e comércio apresentaram os melhores desempenhos no período, $(+8,13 \%)$ e $(+7,58 \%)$, respectivamente. No entanto, em termos relativos, os melhores desempenhos foram os da Construção Civil, com crescimento de 21,41\% (24 mil postos de trabalho).

Os dados acerca da dinâmica paranaense referentes ao emprego mostram que as taxas de inserção no mercado de trabalho, por sexo, mantêm-se distantes ao longo das décadas de 1985 a 2010, com a maior participação dos homens no mercado de trabalho, mas revelando crescimento das taxas de participação feminina. Atualmente, no Paraná, das 2.783.715 vagas existentes, 1.194 .155 são ocupadas por mulheres, ou seja, $43 \%$ das vagas. Isso representa um ganho de $12 \%$ na participação feminina nos últimos 25 anos, uma vez que em 1985 apenas 31\% dos postos de trabalho formais eram ocupados por mulheres (341.666).

O aumento da participação feminina no mercado de trabalho deve-se, entre outros fatores, aos avanços das mulheres na escolarização, aos novos lugares ocupados por elas na sociedade e às trans- formações ocorridas no mercado de trabalho na última década. Além disso, uma nova realidade que ganhou destaque na última década foi o aumento de mulheres chefes de família com cônjuge: de 2001 a 2010 , o crescimento foi de $3,5 \%$ para $14,2 \%$ do total de famílias com ou sem filhos (Ipea, 2010).

É certo também que o número de mulheres tem aumentado em relação ao número de homens no Brasil. Os dados do IBGE (2010) apontam que, em 2008, a população brasileira apresentava $92,4 \mathrm{mi}-$ lhões de homens e 92,7 milhões de mulheres. Já em 2010, esses números passaram para 93,39 milhões de homens e 97,34 milhões de mulheres, reduzindo, assim, o número de homens comparado ao número de mulheres. No entanto, a proporção de crescimento da participação feminina no mercado de trabalho é superior ao crescimento populacional feminino.

Analisando a participação feminina no mercado de trabalho por microrregiões do Estado do Paraná em 1985, a Microrregião de Pitanga apresentava maior participação feminina (37\%) nos empregos formais, seguida das microrregiões de Capanema (36\%), Wenceslau Braz (36\%) e Curitiba (35\%). No mesmo período, a menor participação concentrava-se nas microrregiões de Cerro Azul, Jaguariaíva e Telêmaco Borba, com apenas (19\%), São Matheus, União da Vitória e Ibaiti com $22 \%$.

Os dados podem ser melhor visualizados na Figura 2.

Figura 2 - Número absoluto e relativo do número de mulheres empregadas, por microrregiões do Paraná - 1985

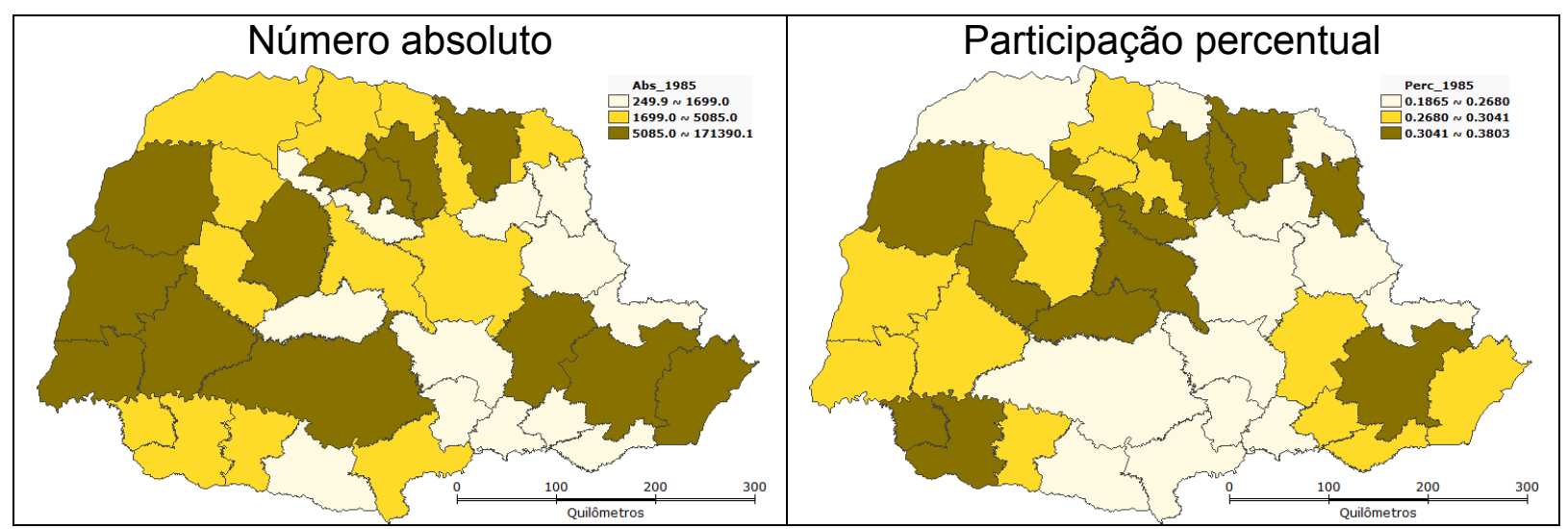

Fonte: Resultados da pesquisa. 
Os dados da participação feminina para 2010 apontam para as microrregiões de Florai (51\%) dos empregos formais, Capanema (48\%), Faxinal (47\%), Foz do Iguaçu (46\%) e Francisco Beltrão e Cornélio Procópio (45\%), com maior participação.
Nesse mesmo período, as microrregiões de Jaguariaíva (32\%), Cerro Azul (33\%), Telêmaco Borba (34\%), Ibaiti (36\%) e Porecatu (36\%) apresentaram os menores índices de emprego formal feminino, conforme mostra a Figura 3.

Figura 3 - Número absoluto e relativo do número de mulheres empregadas, por microrregiões do Paraná - 2010

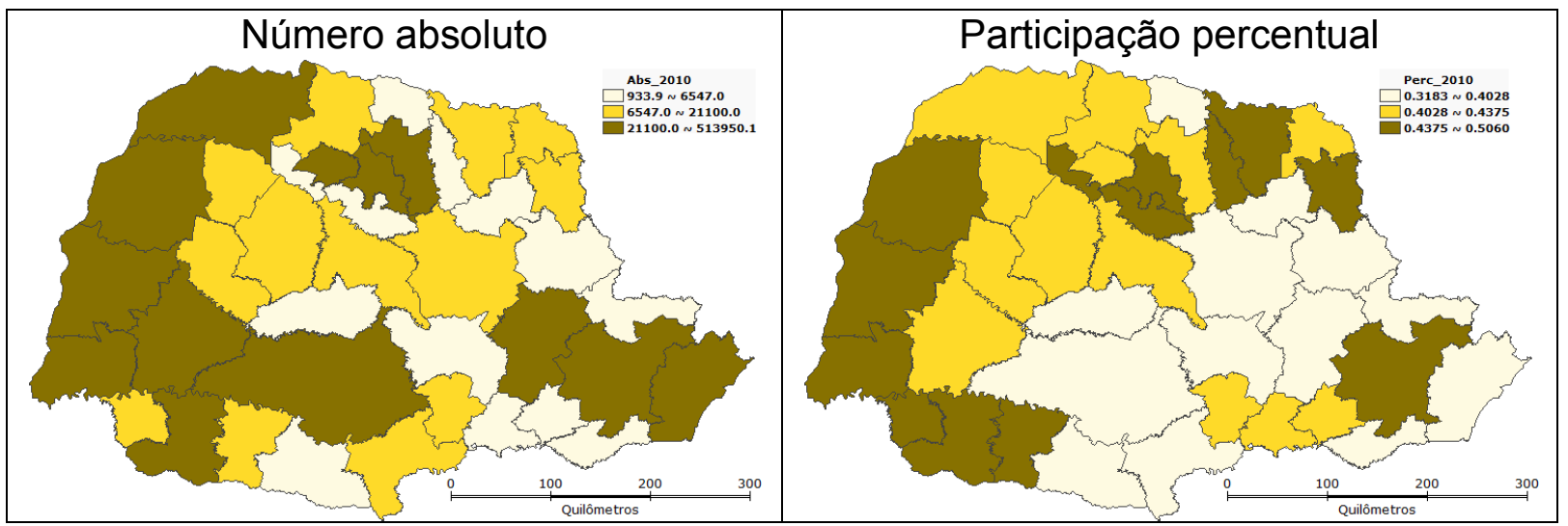

Fonte: Resultados da pesquisa.

Em análise comparativa, observa-se o deslocamento do emprego formal feminino. Ao longo do período de 1985 a 2010, microrregiões como Toledo, Foz do Iguaçu e Pato Branco obtiveram crescimento significativo na taxa de participação feminina no emprego formal, enquanto em outras o índice de crescimento foi menos expressivo, como Londrina, Pitanga e Ivaiporã. Em relação aos subsetores de atividade econômica em que as mulheres atuam, pode-se inferir que, ao longo dos anos, poucas mudanças ocorreram, conforme mostra o Gráfico 2.

Em 1985, as mulheres atuavam de forma mais expressiva nos setores de serviços médicos, odontológicos e veterinários, ocupando $83 \%$ das vagas, seguido dos setores de ensino (70\%), indústria têxtil, do vestuário e artefatos de tecido com $64 \%$ e administração pública direta e autárquica (53\%), serviços de alojamento, alimentação manutenção e redação (43\%). As áreas: extrativa mineral (2\%), construção civil (4\%), indústria de material de transporte $(5 \%)$ e indústria mecânica $(7 \%)$ eram, à época, as menos expressivas.

Comparativamente, em 2010 a maior atuação feminina se concentrava nos subsetores de serviços médicos e odontológicos $(80 \%)$, indústria têxtil, do vestuário e artefatos de tecido (70\%), administração pública direta e autárquica (65\%), ensino (61\%), serviços de alojamento, alimentação manutenção e redação $(59 \%)$ e de forma menos expressiva nos setores de construção civil (7\%), extrativa mineral $(8 \%)$, indústria de produtos minerais não metálicos $(11 \%)$ e indústria de material de transporte (13\%).

Para o mesmo período, os postos de traba1ho, em número absoluto, ocupados por homens concentravam-se nos setores de: comércio varejista (265.548), administração pública (148.932), comércio e administração de imóveis, valores mobiliários, serviços técnicos (135039) e transportes e comunicações (124.980).

Os dados da RAIS (2010) permitem, ainda, visualizar que, entre 1985 e 2010, a indústria de material de transportes obteve o melhor desempenho no que diz respeito à atuação feminina, com crescimento absoluto de $2068 \%$, seguido do setor de ensino com $1379 \%$, e indústria mecânica, com $830 \%$. No entanto, a participação feminina apresentou resultados de crescimento negativos em "outros setores" (-100\%) e crescimento de apenas $40 \%$ nos subsetores de instituições de crédito, seguros e capitalização e $76 \%$ na indústria de produtos minerais não metálicos. 
Gráfico 2 - Participação das mulheres no total do emprego formal no Paraná, por subsetores $1985 / 2010$

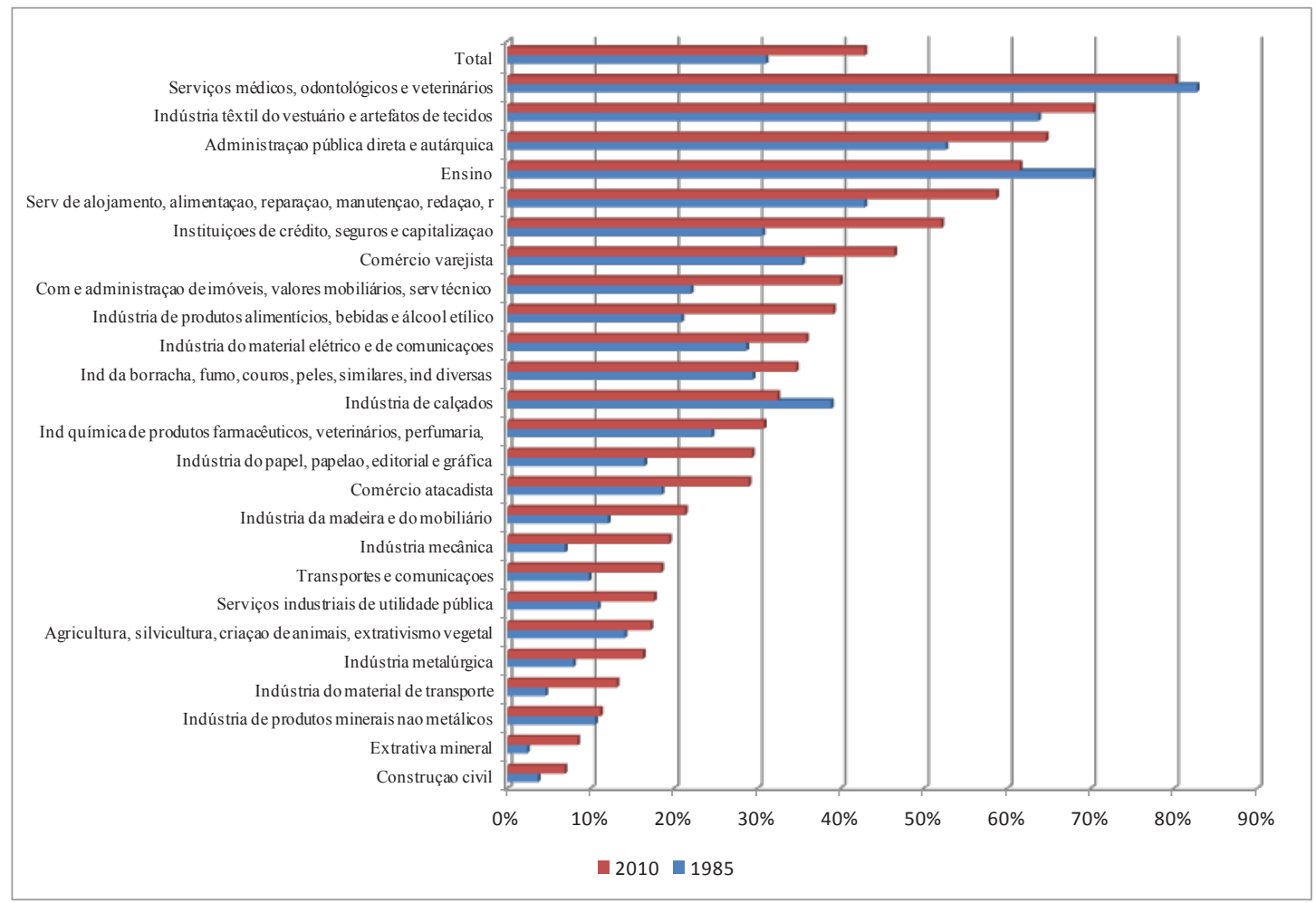

Fonte: Resultados da pesquisa.

Cabe ressaltar que a maior parte das mulheres no Estado do Paraná, a exemplo dos homens, está empregada no setor de serviços, realidade esta presente em todos os estados do Brasil (Caged, 2010). No entanto, as oportunidades geradas para as mulheres no mercado de trabalho continuam associadas à vida privada, aos cuidados da família, e por isso sua inserção profissional acaba sendo, por ora, uma extensão da vida doméstica. Os dados obtidos na pesquisa indicam uma tendência à conformação de nichos ocupacionais femininos, ligados, por exemplo, a educação, saúde e manutenção dos espaços domésticos, tais como empregadas domésticas e prestadoras de serviços de limpeza.

Entretanto, mesmo dentro dessas áreas é possível encontrar a desigualdade entre homens e mulheres. Um exemplo é o setor de ensino, onde grande parte das mulheres professoras encontra-se no ensino básico e fundamental, e os homens predominam no ensino superior. Dados do Ministério da Educação (2010) mostram que, do total de dois milhões de professores identificados pelo Censo Escolar em 2010, 80\% eram do sexo feminino. Já no ensino superior ou educação profissional, onde os salários são mais altos e a estrutura de trabalho é melhor, os índices alteram-se, com predominância do sexo masculino. Apesar de as jovens brasileiras estarem em maioria entre os universitários e entre os doutores desde 2004 (51,5\% do total), elas são menos numerosas que os homens nos cargos de docente. Dos 345 mil professores universitários em exercício, de acordo com o Censo da Educação Superior (2010), 154 mil eram mulheres. Desta forma, pode-se inferir que as diferenças de gênero em postos de trabalho ainda são evidentes e podem ser fruto de discriminação no ambiente de trabalho, ou mesmo decorrentes dos papéis domésticos, muito mais assumidos pelas mulheres.

Quando ocupada, a mulher enfrenta outra dificuldade, que é a desigualdade de remuneração em relação ao homem. Estudos da OIT (2010), no tocante aos rendimentos auferidos do trabalho, apontam para a diminuição da distância de remuneração entre homens e mulheres ao longo da última década. Em 2000, os homens recebiam uma remuneração média 32,5\% superior à das mulheres. Em 2008, 
a remuneração média masculina situou-se em patamar de aproximadamente $29 \%$ acima da remuneração média das mulheres. Apesar dessa diminuição da diferença, as mulheres respondem, majoritariamente, pelos empregos sem remuneração (52,2\%), por ocupações de menor qualificação e relações de trabalho mais precárias e pela maior participação no contingente total da população pobre (as mulheres com rendimento inferior a um salário mínimo representam $18,7 \%$ do total da população feminina ocupada, enquanto os homens com rendimento inferior a um salário mínimo representam $17,1 \%$ da população ocupada masculina).

O estudo da OIT (2010) também apontou que as mulheres brasileiras têm uma jornada semanal superior à dos homens. Muito embora a jornada de trabalho semanal média das mulheres no mercado de trabalho seja inferior à dos homens $(34,8$ contra 42,7 horas), ao computar-se o trabalho realizado no âmbito doméstico a jornada média semanal total das mulheres alcança 57,1 horas, e ultrapassa em quase cinco horas a dos homens (52,3 horas).

Contrapondo as ocupações precárias e os menores salários, mulheres instruídas, além de continuarem marcando presença em tradicionais "guetos" femininos, como o magistério e a enfermagem, têm adentrado também em áreas profissionais de prestígio, como a medicina, a advocacia, a arquitetura e até mesmo a engenharia, tradicional reduto masculino. "Esta poderia ser considerada uma das faces do progresso alcançado pelas mulheres, no que tange à sua participação no mercado de trabalho" (BRUSCHINI, 2007, p.550).

Assim, é possível inferir que a taxa de participação feminina aumentou tanto nos períodos de recessão econômica do Estado do Paraná quanto nos de prosperidade, enquanto a participação masculina tem decrescido.

\section{Conclusões}

O objetivo deste artigo consistiu em mapear o emprego formal feminino do Estado do Paraná, analisando a evolução da inserção desse gênero na estrutura produtiva das 39 microrregiões paranaenses no período compreendido entre 1985 e 2010. A partir dos dados obtidos observou-se aumento do número de mulheres no mercado de trabalho, passando de uma participação de 31\% em 1985 para $43 \%$ do emprego formal paranaense em 2010, reforçando, assim, a evidência empírica de aumento de participação da mulher no mercado de trabalho e consequente redução do diferencial em relação aos homens. Esse crescimento é resultado principalmente de mudanças econômicas, queda da taxa de fecundidade e aumento no nível de instrução da população feminina.

Destaca-se a crescente qualificação e capacitação profissional das mulheres como um dos fatores de maior impacto sobre o ingresso das mulheres no mercado de trabalho. Atualmente, a maior parte do PEA paranaense com nível superior é composto por mulheres, posição essa ocupada historicamente por homens. Igualmente, a qualificação feminina foi responsável pelo aumento dos salários pagos às mulheres em relação aos homens, mas não suficiente para resolver os hiatos entre gênero no mercado de trabalho. Os dados da pesquisa comprovam que as mulheres ainda se encontram ocupadas em atividades mais vulneráveis, recebem rendimentos menores que os dos homens e, por consequência, apresentam maiores chances de ficar desempregadas.

Os dados da pesquisa apontaram também para alterações não apenas na intensidade de engajamento das mulheres no mercado de trabalho, como também nos setores que mais empregam comparativamente ao contingente masculino. Dos 26 (vinte e seis) subsetores analisados, a atuação feminina concentrava-se com maior expressividade, em 2010, a exemplo de 1985, nos subsetores de serviços médicos e odontológicos (83\% em 1985 e 80\% em 2010). Para os subsetores de indústria têxtil, do vestuário e artefatos de tecido, observa-se crescimento nas últimas décadas analisadas, passando de uma taxa de participação feminina de 64\% em 1985 para $70 \%$ em 2010, com destaque para as microrregiões de Goioerê e Ivaiporã (7\% em 1985 para 82\% em 2010, e 8\% em 1985 para 85\% em 2010, respectivamente). Pode-se inferir que o crescimento da participação feminina no setor é fruto principalmente da expansão da indústria têxtil no Paraná, setor historicamente com predominância feminina.

Outro aspecto revelado pela pesquisa foi o decréscimo de $9 \%$ do percentual de mulheres atuando no setor de ensino, passando de $70 \%$ de participação no início do período analisado para 61\% em 2010. 
Tal fato deve-se, entre outros fatores, à expansão do ensino superior, onde os salários são mais altos e predomina o sexo masculino. A pesquisa evidencia, por exemplo, que nas microrregiões que compõem a Mesorregião Oeste do Paraná (Cascavel, Toledo e Foz do Iguaçu), onde o ensino superior obteve significativa expansão nas últimas décadas, a participação feminina tem decrescido. Em Cascavel, de 77\% de participação feminina em 1985, passou-se para $62 \%$ em 2010; em Toledo os índices foram de $87 \%$ para $60 \%$ e em Foz do Iguaçu de $82 \%$ para $58 \%$.

Destaca-se também, o deslocamento espacial da concentração do trabalho formal feminino. Em 1985, a Microrregião de Pitanga apresentava maior participação feminina dos empregos formais (37\%), seguida das microrregiões de Capanema (36\%) e Wenceslau Braz (36\%). Já em 2010, as microrregiões de Florai (51\%), Capanema (48\%) e Faxinal (47\%) despontam com maiores índices de participação desse gênero no mercado de trabalho formal, confirmando, assim, os preceitos teóricos de que o crescimento não ocorre de forma igualitária entre as diversas microrregiões. Ressalte-se que as questões de gênero impactam positivamente no processo de desenvolvimento nas distintas microrregiões.

No entanto, a análise dos dados demonstra também a desigualdade enfrentada pelas mulheres no mercado de trabalho. Os avanços na participação feminina no mercado de trabalho formal, o crescimento dos índices de escolaridade e as mudanças sociais e demográficas das últimas décadas não foram suficientes para reduzir a defasagem em termos percentuais de rendimento das mulheres em relação aos homens, mesmo que esses tenham menor qualificação e desempenhem as mesmas funções, apesar de já terem demonstrado capacidade e competência nos mais variados subsetores econômicos.

Por fim, os resultados apontam para necessidade de aprofundamento da análise dos dados, considerando prioritariamente aspectos como deslocamento espacial e concentração do emprego formal feminino em determinadas microrregiões em detrimento de outras, os quais fogem às possibilidades de discussão deste artigo.

\section{Referências}

ALVES, J. E. D. Questões demográficas: fecundidade e gênero. Rio de Janeiro: Escola Nacional de Ciências Estatísticas, 2004. Disponível em: <http://www.ence.ibge. gov.br>. Acesso em: $10 \mathrm{dez} .2011$.

ALVES, L.; FERRERA DE LIMA, J.; RIPPEL, R.; PIFFER, M. O continuum urbano e rural no Oeste do Paraná no século XXI . In: ENCONTRO NACIONAL DA ASSOCIAÇÃO DE ESTUDOS REGIONAIS E URBANOS (ENABER), 9. Natal. Anais..., 2011.

ANDRADE, M.C. Espaço, polarização e desenvolvimento. São Paulo: Brasiliense, 1973. 125 p.

BORGES, A; GUIMARÃES, I. B. A mulher e o mercado de trabalho nos anos 90: o caso da Região Metropolitana de Salvador. In: DA ROCHA, M. I. B. (Org.). Trabalho e gênero: mudanças, permanências e desafios. Campinas: ABEP, NEPO/UNICAMP E CEDEPLAR/UFMG/São Paulo: Editora 34, 2000.

BOUDEVILLE, J. R. Les spaces économiques. Paris: Press Universitaires de France, 1970.

BRUSCHINI, M. C. A. Trabalho e gênero no Brasil nos últimos dez anos. Cadernos de Pesquisa da Fundação Carlos Chagas, v. 37, n. 132, p. 537-572, set./dez., 2007.

CAGED - Cadastro Geral de Empregados e Desempregado. Boletim do Observatório do Mercado de Trabalho: resumo dos principais indicadores do mercado de trabalho, n. 08, 2010. Disponível em:<http://www.caged.gov.br/>. Acesso em: 05 dez. 2011.

FORTIN, A. Territoires de L'identité, territoires de la culture. Organisations e Territoires. Québec, v.11, n.1, p. 39-42, 2002.

GARCIA, L. S.; CONFORTO, E. A inserção feminina no mercado de trabalho urbano brasileiro e renda familiar. Disponível em: <http://www.fee.tche.br/sitefee/download/ jornadas/2 /h7-03.pdf $\$$. Acesso em: 09 jan. 2012.

GONÇALVES JUNIOR, C. A.; ALVES, L. R.; PARRE, J. L.; LIMA, J. F. Análise diferencial/estrutural e fatorial do emprego nas microrregiões paranaenses entre 2005 a 2009. In: ENCONTRO NACIONAL DA ASSOCIAÇÃO BRASILEIRA DE ESTUDOS REGIONAIS E URBANOS - ENABER, 9, 2011, Natal - RN. Anais..., 2011.

.; LIMA, J. F.; PARRE, J. L. O dinamismo do emprego no Estado do Paraná: um estudo utilizando a variação liquida total entre 2005 a 2009. In: ENCONTRO DE ECONOMIA PARANAENSE, 2011, Maringá. Anais..., 2011.

HEREDIA, B. M. A.; CINTRÃO. R. P. Gênero e acesso a políticas públicas no meio rural brasileiro. Revista NERA, n. 8, p.1-28, Jan./Jun, 2006. 
HESPANHOL, N. A. Dinâmica agroindustrial, intervenção estatal e a questão do desenvolvimento na região de Andradina - Tese de doutorado em Organização do Espaço: Rio Claro IGCE - CP. de Rio Claro - UNESP, 1996.

HOFFMANN, R.; LEONE, E. T. Participação da mulher no mercado de trabalho e desigualdade da renda domiciliar per capita no Brasil: 1981-2002. Nova Economia, Belo Horizonte, v.14, n 2, p.35-58, maio/agosto, 2004.

IBGE - Instituto Brasileiro de Geografia e Estatística. Base de Dados: IBGE Cidades@. Disponível em: <www.ibge. gov.br >. Acesso em: 11 jan. 2012.

Censo demográfico 2010. Disponível em: <http:// www.ibge.gov.br/home/estatistica/populacao/censo2010/ default.shtm>. Acesso em: 11 jan. 2012.

Pesquisa Nacional por Amostra de Domicílios (PNAD) 2009. Disponivel em: <http://www.ibge.gov.br/. Acesso em: 13 jan. 2012.

IPEA. Instituto de Pesquisa Economica Aplicada. Disponível em: <http://www.ipea.gov.br/portal/>. Acesso em: 14 jan. 2012.

LAVINAS, L.; SORJ, B. O trabalho a domicílio em questão: perspectivas brasileiras. In: ROCHA, M. I. B. Trabalho e gênero: mudanças, permanências e desafios. Campinas: ABEP, NEPO/UNICAMP e CEDEPLAR/UFMG, São Paulo: Editora 34, 2000.

LEMOS, M. B. Espaço e capital: um estudo sobre a dinâmica Centro x Periferia. (Tese de Doutorado em Economia). Campinas: Universidade Estadual de Campinas, 1988.

MEC- Ministério da Educação. Censo da educação superior 2010. Disponível em: $<$ http://portal.mec.gov.br $>$. Acesso em: 02 dez. 2011.

MELLO, H. P. O Brasil e o global gender gap index do Fórum Econômico Mundial: algumas considerações. Disponível em: <www.observatoriodegenero.gov.br>. Acesso em: 11 nov. 2011.

MTE - Ministério do Trabalho e Emprego. Relação Anual de Informações Sociais - RAIS. Disponível em: <http:// www.mte.gov.br/rais/default.asp $>$. Acesso em: $15 \mathrm{dez}$. 2011 .

OIT - Organização Internacional do Trabalho. A OIT e a igualdade de oportunidades e tratamento no mundo do trabalho. Brasília, 2010.

PIFFER, M.; AREND, S. C. A agropecuária e as indústrias tradicionais no desenvolvimento regional paranaense no período de 1970 a 2000. Informe Gepec, v. 13, n. 1, jan./ jun., p.107 - 122, 2009.

.; D_ Desenvolvimento regional paranaense a partir da abordagem teórica de Douglass North.
In: SEMINARIO INTERNACIONAL SOBRE DESENVOLVIMENTO (SIDR), 4. Santa Cruz do Sul, 2008. Anais... Santa Cruz do Sul: UNISC, 2008. (CDROM).

SEN, A. K. Desenvolvimento como liberdade. São Paulo: Companhia das Letras, 2000.

Desigualdade reexaminada. Rio de Janeiro: Record, 2001.

STADUTO, J. A. R.; TONDO, I. S. P.; NASCIMENTO, C. A.; WADI, Y. M. Ocupações das mulheres rurais no sul do Brasil: uma perspectiva de gênero. In: CONGRESSO DA SOCIEDADE BRASILEIRA DE ECONOMIA, ADMINISTRAÇÃO E SOCIOLOGIA RURAL - SOBER, 47. Anais... Porto Alegre, 2009.

Recebido em: 23/12/2011. Aprovado para publicação em: 27/04/2012 